\title{
PERCEIVED PARENTAL ATTITUDE IN RELATION TO HEALTHY PERSONALITY OF ADOLESCENTS - AN EXPLORATORY STUDY
}

\author{
Dr. Renjini T $1{ }^{\square}$, Dr. Gopakumar AV 2 四 \\ ${ }^{1}$ Assistant Professor, Department of Psychology, Government College for Women, \\ Thiruvananthapuram, India \\ ${ }^{2}$ Head, Department of Media Studies, Kristu Jayanti College, Bengaluru, India
}

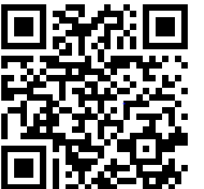

DOI: https://doi.org/10.29121/granthaalayah.v8.i8.2020.997

Article Type: Research Article

Article Citation: Dr. Renjini T, and Dr. Gopakumar AV. (2020).

PERCEIVED PARENTAL ATTITUDE IN RELATION TO HEALTHY PERSONALITY OF ADOLESCENTS AN EXPLORATORY STUDY. International Journal of Research GRANTHAALAYAH, 8(8), 155-163. https://doi.org/10.29121/granthaa layah.v8.i8.2020.997

Received Date: 05 August 2020

Accepted Date: 27 August 2020

Keywords:

Parenting

Adolescence

Healthy Personality

Mental Health

Temperament

\section{ABSTRACT}

The study attempts to find out the relation between parental attitude as perceived by adolescents in the dimensions of autonomy, firm control and psychological control to their healthy personality. The healthy personality is measured in terms of several distinct variables. From this the predictors of healthy personality from parental attitudes is derived. The sample selected were 129 adolescents pursuing under graduation in various colleges in the district of Trivandrum, Kerala state. The questionnaires used were CRPBI (Child's Report of Parent Behavior Inventory) and Healthy Personality questionnaire. Results revealed that the three dimensions of parenting studied have a significant relation to healthy personality of adolescents.

\section{INTRODUCTION}

Parenting in today's world has become a serious area of study. Parenting is now just not going by the instinct or flow. Parents want to give the best and make no mistakes in parenting. Parenting in childhood is different from that in adolescence. When children reach adolescence they pass through behavioral and psychological changes and parents often become confused regarding their parenting at this stage. They look up for professional guidance and it is at this juncture that need for studies in our culture on parenting become relevant. Developing a healthy personality should be one of the goals in parenting to equip one to deal with the ups and downs in life. Though personality is to an extent inherited life experiences and intervention can to an extent modify and mold personality. It is with this intention that factors in parenting which can affect healthy personality is attempted to be studied.

\section{Hypothesis}

There will be significant relation between parental attitudes and healthy personality of adolescents.

(C) 2020 The Author(s). This is an open access article distributed under the terms of the Creative Commons Attribution License, which permits unrestricted use, distribution, and reproduction in any medium, provided the original author and source are credited. 


\section{Objective}

To assess the relation between parenting dimensions and healthy personality of adolescents.

\section{Sample}

College students pursuing undergraduate course in the age group of 17 to 19 were selected for the study ( $N=129$ males 40 females 89). The students were selected from various arts and science colleges in and around Thiruvananthapuram city. Cluster sampling method was followed to select samples from different clusters. Initially 200 samples were selected and questionnaires administered after obtaining consent from the participants and following ethical norms. Incomplete and invalid questionnaires were discarded and finally 129 samples were selected for analysis.
Method
Tools
The following tools were used:
- Child's Report of Parent Behavior -Inventory Schludermann (1988)
- Healthy Personality Profile - Raakhee A.S and Sam Sananda Raj (1997)
- Personal Data schedule

The students were seated in comfortable places. Group tests were conducted. after giving the detailed and specific instructions the students were administered the tests. The data were scored and subjected to statistical analysis.

\section{CRPBI}

CHILD'S REPORT OF PARENT BEHAVIOR INVENTORY (CRPBI 30) Shirin and Eduard Schludermann, Department of Psychology, University of Manitoba, Winnipeg, man. Canada, R3T 2N2. The CRPBI 30 is a shortened version of the 108-item revision by Schludermann and Schludermann (and thereafter called CRPBI -108) of Schaefer's original CRPBI. The CRPBI -30 was intended to be a short instrument which gives information about the three major dimensions on parenting which is equivalent to the much longer CRPBI 108 ie acceptance, firm control and psychological control.

The CRPBI -30 has 30 questions describing the father and 30 questions describing the mother. The items describing the parents are almost identical with only grammatical adjustments for the parents' gender.

\section{HEALTHY PERSONALITY PROFILE (RAAKHEE, A.S \& DR. H. SAM SANANDA RAJ, 1997)}

Healthy personality profile is intended to measure fifteen personality variables under 3 dimensions-Mental health, Temperament and Alienation. It is a Likert type scale with 120 items which were either selected and modified from similar scales or developed for the purpose of the present scale. The scale was developed by Rakhee. A.S and Sam Sanandaraj (1997). For the present study only mental health and temperament subscales were used.

\section{Mental health}

1) Mental health variables

The five variables covered under mental health are the following: Attitude towards the self, Integration, Autonomy, Perception of reality and Environmental mastery

2) Temperament

Temperament is one of the modalities of personality. Temperament traits have to do with the manner in which an individual's actions occur. The variables measured under temperament are the following: Inferiority, Selfsufficiency, Sociability, Stability and Objectivity

\section{Procedure}

The students were seated in comfortable places. Group tests were conducted. after giving the detailed and specific instructions the students were administered the tests. The data were scored and subjected to statistical 
analysis. For this study parametric inferential test has been used. The assumptions underlying parametric statistics are:

- scores have been randomly sampled from the population.

- sampling distribution of the mean is normal.

- within group variances are homogenous. (Bordens, 2006)

The final scores were subjected to statistical analysis using SPSS software

\section{RESULTS}

First the correlation of parenting variables with healthy personality was done. After this multiple regression was carried out to find out the predictor variables.

\subsection{CORRELATES OF HEALTHY PERSONALITY}

In the first step correlation of parental variables with healthy personality variables was conducted. Here parenting variables were observed in relation to healthy personality.

Table 1.1: Correlation coefficients of healthy personality of adolescent with the study variables

\begin{tabular}{|c|c|c|c|}
\hline Variable & Correlation & \%variance & Significance \\
\hline Father acceptance & .298 & 8.4 & .01 \\
\hline Father psychological control & -.282 & 7.84 & .01 \\
\hline Father firm control & -.278 & 7.29 & .01 \\
\hline Mother acceptance & .289 & 8.4 & .01 \\
\hline Mother psychological control & -.156 & 2.25 & Ns \\
\hline Mother firm control & -.285 & 7.84 & .01 \\
\hline
\end{tabular}

Healthy personality of adolescent is positively correlated with father acceptance and mother acceptance. All the positive correlation coefficients obtained in the case of healthy personality are significant at .01 level.

Healthy personality was negatively correlated with father's psychological control, father's firm control and mother's firm control. All the correlation coefficients are significant at .01 level.

Firm control by both parents as well as psychological control by father is seen to have negative relation with healthy personality. As inferiority scores increases the healthy personality scores is seen to come down.

Studies have shown that adolescents whose parents were less accepting, more psychologically controlling and more firm were less able to negotiate with others in conflict situations at ages 16 and 18 and also had decreased ability to negotiate from age 16 to 18. (Geary, 1996). Low levels of acceptance by parents was also found to lead to adolescent problem behavior (Annalise, 1999)

\subsection{CORRELATES OF MENTAL HEALTH}

The correlates of mental health with parenting variables and healthy personality variables were observed. The results are as follows.

Table 1.2: Correlation coefficients of mental health of adolescents with the study variables

\begin{tabular}{|c|c|c|c|}
\hline Variable & Correlation & \%variance & Significance \\
\hline Father acceptance & .261 & 6.76 & .01 \\
\hline Father psychological control & -.263 & 6.76 & .01 \\
\hline Father firm control & -.223 & 4.84 & .05 \\
\hline Mother acceptance & .278 & 7.29 & .01 \\
\hline Mother psychological control & -.092 & 0.81 & $\mathrm{~ns}$ \\
\hline Mother firm control & -.223 & 4.84 & .05 \\
\hline
\end{tabular}


Perceived Parental Attitude in Relation to Healthy Personality of Adolescents - An Exploratory Study

\begin{tabular}{|c|c|c|c|}
\hline Inferiority & -.536 & 28.09 & .01 \\
\hline Self sufficiency & .472 & 22.09 & .01 \\
\hline Sociability & .462 & 21.16 & .01 \\
\hline Stability & .650 & 42.25 & .01 \\
\hline Objectivity & -.625 & 38.44 & .01 \\
\hline Temperament & .716 & 56.41 & .01 \\
\hline Healthy personality & 920 & 84.64 & .01 \\
\hline
\end{tabular}

Table No: 1.2 reveals that the mental health of adolescents is positively correlated with father's acceptance, mother's acceptance, self-sufficiency, sociability, stability, temperament and healthy personality. All the correlation coefficients were significant at .01 level. The negative correlates are father's psychological control, father's firm control, mother's firm control and inferiority all at .01 level of significance. The results of the present study show the importance of acceptance by both parents towards developing good mental health.

The negative correlation of father's psychological control, father's firm control and mother's firm control indicates that too much control by parents affects the adolescent's mental health in a negative way. The negative effect of too much parental control has been supported by studies by (Geary, 1996), (Annalise, 1999).

\subsection{CORRELATES OF TEMPERAMENT}

Temperament is one of the modalities of personality. Temperament traits have to do with the manner in which an individual's actions occur. Here, the variables measured under temperament are inferiority, self-sufficiency, sociability, stability and objectivity.

Table 1.3: Correlation coefficients of temperament of adolescent

\begin{tabular}{|c|c|c|c|}
\hline Variable & Correlation & \%variance & Significance \\
\hline Father acceptance & .290 & 8.41 & .01 \\
\hline Father psychological control & -.259 & 6.25 & .01 \\
\hline $\begin{array}{c}\text { Father firm } \\
\text { control }\end{array}$ & -.290 & 8.41 & .01 \\
\hline Mother acceptance & .259 & 6.25 & .01 \\
\hline Mother psychological control & -.194 & 3.61 & .05 \\
\hline $\begin{array}{c}\text { Mother firm } \\
\text { control }\end{array}$ & -.302 & 9 & .01 \\
\hline Attitude towards self & .588 & 33.64 & .01 \\
\hline Integration & .644 & 40.96 & .01 \\
\hline Autonomy & .430 & 18.49 & .01 \\
\hline Perception of reality & .411 & 16.81 & .01 \\
\hline Environmental mastery & .647 & 40.96 & .01 \\
\hline Mental health & .716 & 50.41 & .01 \\
\hline Healthy personality & .932 & 86.49 & .01 \\
\hline
\end{tabular}

The positive correlates of temperament of adolescent are father acceptance, mother acceptance, and attitude towards self, integration, autonomy, perception of reality, environmental mastery, mental health and healthy personality All the correlation coefficients obtained in the case of the above variables were significant at .01 level.

The negative correlates of temperament are father psychological control, father firm control, mother firm control and inferiority at .01 level of significance and mother psychological control at .05 level of significance.

Psychological control and firm control by parents are seen to have negative relation with temperament. Though the correlation coefficients indicate low levels they are significant at .01level which indicate that they have a role in temperament 


\section{MULTIPLE REGRESSION ANALYSIS}

\subsection{HEALTHY PERSONALITY}

Step wise multiple regression analysis was conducted to find out the predictors of healthy personality of the adolescent from the variables related to parenting dimensions. The obtained results are given below.

Table: 2.1: Results of multiple regression analysis with healthy personality as dependent variable

\begin{tabular}{|c|c|c|c|c|c|c|c|c|}
\hline Sl. No & Variable & $\mathrm{B}$ & Std. Error & Beta & $\mathrm{R}$ & $\mathrm{R}^{2}$ & $\mathrm{~F}$ & Sig. \\
\hline 1 & Father acceptance & 1.89 & .842 & .212 & .298 & .089 & & \\
\cline { 1 - 7 } 2 & Father psychological control & -3.86 & .830 & -.372 & .446 & .199 & \multirow{3}{*}{13.26} & .01 \\
\hline 3 & Mother acceptance & 2.20 & .834 & .253 & .491 & .242 & & \\
\cline { 1 - 6 } & Constant & 384.99 & 21.52 & -- & -- & -- & & \\
\hline
\end{tabular}

The final regression equation for healthy personality of adolescent consisted of three variables viz, father acceptance, father psychological control and mother acceptance.

A linear combination of the above three variables explained a total of 24.2 percent of variance in healthy personality of adolescent. The multiple correlation (R) was 0.491 and $\mathrm{R}^{2}$ was 0.242 . The $\mathrm{F}$ value obtained from the ANOVA test is 13.26 (significance at .01 level), which indicates that the model as a whole is statistically significant in predicting healthy personality. From the table it can be seen that the beta value of father psychological control is highest which indicates that this variable is related most to healthy personality but in an inverse manner. The following regression equation is formulated with the help of obtained B weights and constant value

$\mathrm{Y}=384.992+1.89 \mathrm{X} 1+3.86 \mathrm{X} 2+2.20 \mathrm{X} 3$, where $\mathrm{Y}=$ Healthy personality, $\mathrm{X} 1=$ father acceptance, $\mathrm{X} 2=$ father psychological control and $\mathrm{X} 3=$ mother acceptance.

It can be thus concluded that acceptance by both parents is a predictor of healthy personality of the adolescent. Psychological control especially by father has a negative effect on healthy personality. Mc leod (2007) has also found that excessive parental control may play a particularly important role in adolescent's anxiety disorders either as a cause of anxiety as a response of parents to the adolescent's anxiety or as an expression of the parent's own anxiety.

The predictors of healthy personality in adolescent are father acceptance, father psychological control and mother acceptance.

\section{MENTAL HEALTH}

Multiple regression analysis on mental health with parenting dimensions and temperament variables. Step wise regression analysis was conducted to find out the predictors of adolescent mental health Two predictor variables were identified, namely adolescent mother acceptance and adolescent father psychological control.

Table 3: Results of multiple regression analysis with Mental Health as dependent variable.

\begin{tabular}{|c|c|c|c|c|c|c|c|c|}
\hline Sl no & Variable & B & SE & Beta & R & $\mathrm{R}^{2}$ & F & Sig \\
\hline 1 & Mother acceptance & 1.600 & .371 & .355 & .278 & .077 & & \\
\cline { 1 - 7 } 2 & Father psychological control & -1.846 & .443 & -.343 & .435 & .189 & & \\
\cline { 1 - 5 } & Constant & 178.948 & & & & & 14.697 & 0.01 \\
\hline
\end{tabular}

The final regression equation for adolescent mental health consisted of two variables viz, adolescent mother acceptance and adolescent father psychological control.

A linear combination of the two variables explained 18.9 percent of the variance in mental health. The multiple correlation was 43.5 and $\mathrm{R}^{2}$ was 18.9. The $\mathrm{F}$ value obtained from the ANOVA test is 14.697 and significance is at 0.01 level, which indicates that the model as a whole is statistically significant in predicting adolescent mental health.

The following regression equation is formulated with the help of obtained B weights and constant value.

$\mathrm{Y}=178.948+1.600 \mathrm{X} 1+1.846 \mathrm{X} 2$ where $\mathrm{Y}=$ mental health, $\mathrm{X} 1=$ mother acceptance, $\mathrm{X} 2=$ father psychological control. 
When the result is compared with that of correlation result it can be seen that mother acceptance is positively correlated at .01 level and father psychological control is correlated negatively at .01 level of significance. The effect size is 7.29 and 6.76 respectively.

From the above results we can conclude that psychological control by father contributes negatively to mental health and that higher the acceptance given by mother higher the mental health of the adolescent.

(George 2011) in a study conducted among teenagers in Kerala found that acceptance shown by mother had significant positive relation with problem solving confidence of adolescents. Higher levels of maternal acceptance during adolescence was also found to forecast lower levels of early adult internalizing problems. (Jones, 2000)

The parenting variables that can predict mental health in adolescent are acceptance by mother and psychological control by father.

\section{MENTAL HEALTH WITH TEMPERAMENT VARIABLES}

Step wise multiple regression analysis was conducted to find out the predictors of adolescent mental health from temperament variables. Three predictor variables were identified viz, stability of adolescent, objectivity of adolescent and self sufficiency of adolescent. The obtained results are given below.

Table 4: Results of regression analysis with mental health as dependent variable.

\begin{tabular}{|c|c|c|c|c|c|c|c|c|}
\hline Sl no & Variable & $\mathrm{B}$ & SE & Beta & $\mathrm{R}$ & $\mathrm{R}^{2}$ & $\mathrm{~F}$ & Sig \\
\hline 1 & Stability & 1.267 & .246 & .401 & .650 & .423 & & \\
\cline { 1 - 9 } 2 & Objectivity & 1.303 & .337 & .312 & .715 & .511 & & \\
\cline { 1 - 7 } 3 & Self sufficiency & .664 & .311 & .152 & .727 & .528 & 46.623 & \multirow{2}{*}{0.01} \\
\hline & Constant & 84.527 & 11.815 & & & & & \\
\hline
\end{tabular}

The final regression equation for adolescent mental health consisted of three variables viz, stability of the adolescent, objectivity of the adolescent, and self sufficiency of the adolescent. The results also show that a linear combination of stability of adolescent, objectivity of adolescent and self sufficiency of adolescent explained 52.8 percent of variance in mental health of the adolescent. The multiple correlation(R) was 0.727 and $\mathrm{R}^{2}$ was 0.528 .This is a statistically significant contribution, as indicated by the $\mathrm{F}$ value for this line .The $\mathrm{F}$ value is 46.623 and significance level is at 0.01 . From this we can infer that the variable stability of the adolescent is the highest predictor of adolescent mental health followed by objectivity of the adolescent and then self sufficiency of the adolescent.

$\mathrm{Y}=84.527+1.267 \mathrm{X} 1+1.303 \mathrm{X} 2+.664 \mathrm{X} 3$ where $\mathrm{Y}=$ Mental health, $\mathrm{X} 1=$ stability, $\mathrm{X} 2=$ objectivity X3= Self-sufficiency.

Hence from among the temperament variables the variables that can contribute to high mental health are stability, objectivity and self-sufficiency. When a person has high mental health it implies that the person is independent in personal matters, he is relatively unchanged and can observe events realistically. The predictor variables of mental health of adolescent from temperament variables are stability, objectivity and self-sufficiency.

\section{TEMPERAMENT OF ADOLESCENT}

Stepwise regression was then conducted to find out the predictors of temperament of adolescent from the variables of the adolescent related to parenting dimensions. Three predictor variables were identified. They are adolescent mother firm control, adolescent father acceptance and adolescent father psychological control.

Table 5: Result of regression analysis of temperament of adolescent as dependent variables.

\begin{tabular}{|c|c|c|c|c|c|c|c|c|}
\hline Sl No. & Variable & B & SE & Beta & $\mathrm{R}$ & $\mathrm{R}^{2}$ & $\mathrm{~F}$ & Sig \\
\hline 1 & $\begin{array}{l}\text { Mother firm } \\
\text { control }\end{array}$ & -1.170 & .471 & -.204 & .302 & .091 & \multirow{4}{*}{11.589} & \multirow{4}{*}{0.01} \\
\hline 2 & Father acceptance & 1.482 & .408 & .297 & .387 & .150 & & \\
\hline \multirow[t]{2}{*}{3} & Father psychological control. & $-1,570$ & .476 & -.270 & .466 & .218 & & \\
\hline & constant & 215.926 & 14.807 & & & & & \\
\hline
\end{tabular}


The final regression equation for temperament of adolescent consisted of three variables from among the parenting variables of father and mother. They are adolescent mother firm control, adolescent father acceptance and adolescent father psychological control. The linear equation shows that the three variables together contributed 21.8 percent to overall temperament of adolescent. The F value obtained from the ANOVA test is 11.589 and significance is at .01 level which indicate that the model as a whole is statistically significant in predicting the temperament of adolescent. The following regression equation is formulated with the help of obtained B weights and constant value.

$\mathrm{Y}=215.926+1.170 \mathrm{X} 1+1.482 \mathrm{X} 2+1.570 \mathrm{X} 3$ where $\mathrm{Y}=$ temperament, $\mathrm{X} 1=$ mother firm control, $\mathrm{X} 2=$ father acceptance, $\mathrm{X} 3=$ father psychological control.

When the results from correlation table is taken father acceptance is positively correlated at .01 level, effect size is 8.41. Father psychological control and mother firm control is correlated negatively at .01 level of significance. Effect size is 6.21 and 9 percent respectively. If father is unable to convey acceptance, support and mother failed to provide firm control then adolescent is at increased risk for acting out behaviors. Here some amount of firm control by mother is advised (Jones, 2000)

The three variables viz, adolescent mother firm control, adolescent father acceptance and adolescent father psychological control together contribute 21.8 percent of the total variance in temperament of adolescent. It can be seen that the beta value of adolescent father acceptance was the highest. So we can conclude that the variable adolescent father acceptance has the highest influence on temperament of the adolescent among the parental dimensions and it has a positive effect in predicting temperament of adolescent.

High firm control by mother and high psychological control by father, both can contribute to a negative temperament in adolescent. Higher levels of maternal firm control during adolescence were associated with more secure early adult romantic attachment but low levels of educational achievements. (Jones, 2000). The predictor variables of temperament of adolescent are mother firm control, father acceptance and father psychological control.

\section{MULTIPLE REGRESSION ANALYSIS OF TEMPERAMENT WITH HEALTHY PERSONALITY VARIABLES}

Step wise multiple regression analysis was then conducted to find out the predictors of temperament of adolescent with healthy personality variables. The variables entered were attitude towards self of adolescent, integration of adolescent, autonomy of adolescent, perception of reality of adolescent and environmental mastery of adolescent. Of the variables entered the variables found to be related were environmental mastery of adolescent, integration of adolescent and attitude to self of adolescent.

Table 6: Results of regression analysis of Temperament as dependent variable

\begin{tabular}{|c|c|c|c|c|c|c|c|c|}
\hline Sl no & Variable & B & SE & Beta & R & $\mathrm{R}^{2}$ & F & Sig \\
\hline 1 & Environmental mastery & 1.150 & .310 & .313 & .647 & .418 & & \\
\cline { 1 - 8 } 2 & Integration & 1.408 & .352 & .327 & .716 & .512 & & \\
\cline { 1 - 7 } 3 & Attitude towards self & .936 & .354 & .212 & .734 & .538 & 48.547 & 0.01 \\
\hline & Constant & 50.633 & 12.604 & & & & & \\
\hline
\end{tabular}

A linear combination of these three variables viz, environmental mastery of adolescent, integration of adolescent and attitude towards self of adolescent explained a total of 53.8 percent of variance in overall temperament. The multiple correlation was .734 and $\mathrm{R}^{2}$ was. 538. The $\mathrm{F}$ value obtained from the ANOVA test is 48.547 and significance is at .01 level which indicates that the model as a whole is statistically significant in predicting temperament of the adolescent. When the beta values of the three variables are compared it can be seen that the value of environmental mastery of adolescent is .313, that for integration of adolescent .327 and that of attitude towards self of adolescent is .212. From this we can conclude that the highest influence on temperament is by the variable integration of the adolescent. The positive values of all the three variables indicate the positive effect of these variables on temperament of the adolescent.

The following regression equation is formulated with the help of obtained B weights and constant value

$\mathrm{Y}=50.633+1.150 \mathrm{X} 1+1.408 \mathrm{X} 2+.935 \mathrm{X} 3$ where $\mathrm{Y}=$ temperament of adolescent, $\mathrm{X} 1=$ environmental mastery, $\mathrm{X} 2=$ integration $\mathrm{X} 3=$ attitude towards self 
When the results of correlation table is considered it can be seen that environmental mastery is correlated positively at .01 level of significance, effect size is 40.96, integration of adolescent effect size 40.96 and attitude towards self-effect size 33.64 percent, both correlated at .01 level positively with temperament. The predictor variables of adolescent from healthy personality variables are environmental mastery, integration and attitude towards self.

\section{CONCLUSION}

It can be thus concluded that acceptance by both parents is a predictor of healthy personality of the adolescent. Psychological control especially by father has a negative effect on healthy personality. Psychological control by father contributes negatively to mental health and higher the acceptance given by mother higher the mental health of the adolescent.

The variable stability of the adolescent is the highest predictor of adolescent mental health followed by objectivity of the adolescent and then self-sufficiency of the adolescent. High firm control by mother and high psychological control by father, both can contribute to a negative temperament in adolescent. The predictor variables of adolescent from healthy personality variables are environmental mastery, integration and attitude towards self.

\section{LIMITATIONS}

- The sample size could have been more

- The study could have been extended to different places.

\section{SOURCES OF FUNDING}

This research received no specific grant from any funding agency in the public, commercial, or not-for-profit sectors.

\section{CONFLICT OF INTEREST}

The author have declared that no competing interests exist.

\section{ACKNOWLEDGMENT}

None.

\section{REFERENCES}

[1] Bordens, K.S., \& Abbott, B.B. (2006). Research Design and Methods (6th ed). New Delhi: Tata McGraw Hill.

[2] George, S. (2011). Effect of child-rearing practices on stress tolerance and problem solving among teenagers. Unpublished thesis. University of Kerala.

[3] Geary, C.A. (2012). Adolescent Autonomy with Parents as a Predictor of Low Susceptibility to Peer Pressure Distinguished Majors Thesis University of Virginia12.

[4] Jones, D.F. \& Beach, S. (2000). Maternal and paternal parenting during adolescence:forecasting early adult psychosocial adjustment. Adolescence, Sept 22.

[5] Leary,M.R. \& Baumister,R.F.(2000).The nature and function of self-esteem; Sociometer theory in M.P.Zanna (ed) ,Advances in experimental social psychology vol32 SanDiego ,CA:Academic

[6] Mcleod B.D., Wood.J \& John, R.W. (2007). Examining the association between parenting and childhood anxiety A meta-analysis. Clinical psychology review 27, 155-172.

[7] Raakhee, A. S. (1998) Mental health, temperament and alienation of the aged, unpublished thesis, University of Kerala 
[8] Schludermann, S.M., \& Schludermann, E.H., (1983) Sociocultural change and adolescents' perceptions of parent behavior. Developmental Psychology, 19 (5), 674-685. 